\title{
Identification of habitat controls on northern red-legged frog populations: implications for habitat conservation on an urbanizing landscape in the Pacific Northwest
}

Lauren A. Grand ${ }^{1 *}$, Marc P. Hayes ${ }^{2}$, Kristiina A. Vogt ${ }^{3}$, Daniel J. Vogt ${ }^{3}$, Paul R. Yarnold ${ }^{4}$, Klaus O. Richter ${ }^{5}$, Christopher D. Anderson ${ }^{6}$, Elissa C. Ostergaard ${ }^{7}$ and Jo O. Wilhelm ${ }^{7}$

\begin{abstract}
Introduction: In the Pacific Northwest of North America, research addressing lentic-breeding amphibian population vulnerability has emphasized aquatic habitats, frequently neglecting terrestrial habitats. Consequently, wetland protection and restoration often fails to preserve or restore adjacent uplands required by lentic-breeding amphibians. Inattention to the juxtaposition and connectivity of uplands to wetlands could locally extirpate lentic-breeding amphibians. The objective of this research is to identify the relative importance of juxtaposed terrestrial and aquatic habitats in a lentic-breeding amphibian, the northern red-legged frog (Rana aurora), by evaluating the relationship between its occurrence and abundance with its aquatic and terrestrial habitats. To accomplish this, egg mass counts were used to quantify $R$. aurora populations in 30 stillwater habitats across an urbanization gradient. Using a Geographic Information System, seven descriptors of aquatic and surrounding terrestrial habitats were measured to evaluate their relationships to $R$. aurora occurrence and abundance.

Results: Rana aurora occurrence and breeding abundance both reflect the forested area around wetland breeding sites and forest connectivity to those sites. Rana aurora breeding abundance also strongly reflects the percent of forested perimeter around wetland breeding sites. The forest habitat most important for $R$. aurora breeding abundance seems to be $>200 \mathrm{~m}$ from the breeding wetlands. The American bullfrog presence and the two aquatic parameters measured, wetland area and vegetated area, were unrelated to $R$. aurora occurrence and breeding abundance.

Conclusions: Area and connectivity of juxtaposed forested terrestrial habitat may represent a basic control on $R$. aurora presence and population size. Urban development policies should consider preservation and restoration of upland forest habitats beyond current fixed-width buffers and wetland habitat area at landscape scales.
\end{abstract}

Keywords: Northern red-legged frog, Amphibian habitat, Rana aurora, Land use, Landscape planning, Urban landscapes, Amphibian population

\footnotetext{
* Correspondence: lauren.grand@oregonstate.edu

${ }^{1}$ College of Forestry, Oregon State University, 996 Jefferson St, Eugene, OR

97402, USA

Full list of author information is available at the end of the article
} 


\section{Introduction}

Maintaining populations of species with complex life histories that migrate between different habitats is challenging in human-altered landscapes. Terrestrial upland habitats are fragmented by roads (Trombulak and Frissell 2000) or replaced by buildings (Lehtinen et al. 1999), and wetland breeding sites may be altered or eliminated entirely (Dodd and Smith 2003). Outside of the US Pacific Northwest (PNW), such habitat alteration has been linked to declines in amphibian species richness (Lehtinen et al. 1999) or declines in the local populations of lenticbreeding amphibians that require terrestrial habitat juxtaposed to wetlands (Pope et al. 2000; Semlitsch 2000; Semlitsch and Bodie 2003). In the PNW, because most lentic-breeding amphibians require both terrestrial and aquatic habitats to complete their lifecycles, connectivity between these habitats is critical for maintaining local populations. Consequently, lentic-breeding amphibians may be threatened to varying degrees in human-altered landscapes featuring loss of breeding wetlands, adjacent non-breeding forested habitats, and landscape connectivity (Gibbs 2000).

The PNW has one of the fastest growing conurbations in North America (Pivo 1996). In Washington State, human population density increased by $13 \%$ between $2000\left(2116\right.$ persons $\left./ \mathrm{km}^{2}\right)$ and 2012 (2395 persons $\left./ \mathrm{km}^{2}\right)$ (US Census Bureau 2015). Washington State's most populous county, King County, reached a total population of 2,044,449 in 2013 (US Census Bureau 2015) and is predicted to double by 2040 (WOFM [Washington Office of Financial Management] 2012). This extraordinary growth raises concerns that the forested landscape will be further fragmented as urbanization increases (Pivo 1996, Butler et al. 2004, McKee et al. 2004, Luck 2007). Attendant rapid changes in forested landscapes threaten the viability of wildlife dependent upon forest habitat for part of their lifecycle.

Over a decade has elapsed since McKinney (2002) emphasized the paucity of studies addressing urbanization impacts on native animal species (Scheffers and Paszkowski 2012). This statement is particularly relevant for amphibians in the PNW (Hayes et al. 2008). Accordingly, the goal of the present research was to examine how loss of forested terrestrial habitat due to urbanization is impacting the northern red-legged frog (Rana aurora), a lentic-breeding amphibian widespread in the mesic PNW. Rana aurora is the ideal amphibian to assess urbanization impacts because it is seasonally dependent on coupled aquatic (reproductive) and terrestrial (non-breeding active season) habitats and migrates seasonally long distances (to at least $5 \mathrm{~km}$ ) utilizing a mosaic of aquatic and terrestrial habitats (Hayes et al. 2008). Habitat loss and fragmentation are more likely to affect migrating lentic-breeding amphibians such as $R$. aurora compared to other amphibians whose life history phases are predominantly within aquatic habitats and/or are strongly riparian associated (Hayes et al. 2008).

Although diverse studies of amphibian assemblages report strong associations between amphibian richness and composition of the surrounding landscape (Laan and Verboom 1990; Knutson et al. 1999; Lehtinen et al. 1999), projects designed to protect and restore wetlands infrequently consider the surrounding uplands also needed by amphibians. This issue may be critically important in maintaining the population levels of lenticbreeding amphibians in the PNW - where forests are the primary upland habitat utilized during their lengthy non-breeding active season (Nussbaum et al. 1983; Martin and McComb 2003; Pearl et al. 2005; Hayes et al. 2008). If specific connectivity needs exist between the terrestrial and aquatic habitats that these amphibians require, then projecting how future land-use change might affect amphibian population dynamics may be facilitated (Cole et al. 1997; White et al. 1997).

The quantity and distribution of forested habitat needed to sustain $R$. aurora in the PNW is largely undocumented (Hayes et al. 2008). This study was designed to assess the habitat needs of $R$. aurora and to identify relationships as well as possible threshold criteria that exist between the jutxaposed mosaic landscape of aquatic and terrestrial habitats and $R$. aurora population levels. The present research describes the relationship between $R$. aurora occurrence and abundance and the terrestrial habitat (including forested area, its connectivity, and percent of forested wetland perimeter), as well as wetland characteristics (including wetland size and emergent vegetation). These data should help to identify conservation needs and strategies for lentic-breeding amphibians requiring both aquatic and terrestrial habitats at spatial scales within the seasonal habitat footprint used by $R$. aurora.

\section{Methods}

Site description and selection

Rana aurora populations were surveyed across selected wetlands within the greater Seattle area of western King County, Washington State, USA. King County is bordered by Puget Sound on the west and the Cascade Mountains on the east. Temperate moist forests dominate the less developed (eastern) portion of the study area (Franklin and Dyrness 1973). Wetlands diverse in size, shape, and type are imbedded across this landscape.

Geographic Information System (GIS) spatial tools were used to identify which wetlands within the water body dataset from the King County data portal meet the criteria for our survey (ESRI 2011; King County 2010). Initially, all open water wetlands below $800 \mathrm{~m}$ in elevation were located to minimize the likelihood of selecting 
wetlands above $R$. aurora's local elevation range (Nussbaum et al. 1983; Dvornich et al. 1997). Wetlands within $200 \mathrm{~m}$ of another wetland were excluded from the survey to ensure that independent breeding populations of $R$. aurora were being considered. Rana aurora adults are known to make exploratory movements among potential breeding sites during the post-winter thaw pre-breeding period, but such movements are not known to exceed $150 \mathrm{~m}$ (M. Hayes, unpublished data). Such movements are distinguishable from the back-andforth migrations adults make between aquatic breeding habitat to which adults return annually with high site fidelity, and upland forested habitat where the nonbreeding active season is spent (Licht 1974, Hayes et al. 2008). Human-constructed stormwater ponds were also excluded from this study.

In total, 1006 wetlands fulfilled the aforementioned selection criteria. Wetlands larger than 1.5 ha were excluded to ensure sampling effectiveness. Also, larger wetlands are more likely to be permanently flooded and have a higher predominance of exotic-invasive predators which negatively affect the occurrence of $R$. aurora (Adams 1999; M. Hayes, unpublished data). Wetlands under 1.5 ha encompass over 93\% (2582 total wetlands and $2406<1.5 \mathrm{ha}$ ) of the total number of wetlands in $R$. aurora's local breeding range, and 88\% (1006 total wetlands and $883<1.5 \mathrm{ha}$ ) of the wetlands that fell within the parameters of this study. For the remaining 883 wetlands, the percentage of surrounding forest area was determined within a $5-\mathrm{km}$ footprint perpendicular from the edges of each wetland. A maximum distance of $5 \mathrm{~km}$ was used because $R$. aurora adults have been recaptured at straight-line distances of $5 \mathrm{~km}$ from their breeding ponds (Hayes et al. 2001; Hayes et al. 2007). Wetlands were then categorized across two strata to adequately characterize the variability in forest cover and wetland size for site selection. These strata included: (1) five categories of surrounding forest cover $(\leq 17 \%$, $>17-33 \%,>33-50 \%,>50-66 \%,>66-100 \%)$ and (2) three evenly distributed categories of wetland size $(\leq 0.50$ ha, $>$ 0.5-1.0 ha, and >1.0-1.5 ha). The greatest forest cover category was twice the size of other categories because few wetlands existed where forest cover values were $>66 \%$. Combined strata resulted in 15 different categories.

From this pool of wetlands, two categories within each of the 15 habitat categories were randomly chosen for this study, totaling 30 habitat categories (Fig. 1). Wetlands were then visited to ensure that they satisfied the selection criteria and that they had not been altered after the GIS dataset was created. Wetlands less than $0.6 \mathrm{~m}$ deep, and/or with vegetation that shaded them for most of the day, were excluded from the study database as being either too ephemeral or too shaded to be used by $R$. aurora (Licht 1969, 1971). Excluded wetlands were replaced by the next wetland in the random sequence within the same habitat category.

\section{Data collection}

\section{Landscape and aquatic habitat}

All aquatic habitat and landscape features were estimated in ArcGIS 10.0 (ESRI 2011). Wetland area was estimated using the Geometry Field Calculator. Percent forest cover was estimated using the 2006-era classification of the US West Coast Region, zone 1 Landsat raster data with an accuracy of $86.1 \%$ and grain size of $90 \times 90 \mathrm{~m}$ (DOC et al. 2008). These Landsat data were differentiated into 21 class types, but four classes (Deciduous Forest, Evergreen Forest, Mixed Forest, and Palustrine Forested Wetland) were collapsed into one "Forest" category.

Following this reclassification, percent forest area of the landscape surrounding each wetland was calculated using FRAGSTATS (v4.0) (McGarigal et al. 2012). Percent forest was calculated at 19 different distances from the wetlands in cumulative concentric footprints extending outward from the wetland edge every $50 \mathrm{~m}$ up to a distance of $500 \mathrm{~m}$ and subsequently every $500 \mathrm{~m}$ up to $5 \mathrm{~km}$ (Fig. 2). These nested footprints were used to characterize different habitat configurations across $R$. aurora's migratory pathway.

For each wetland, the following calculations were made: percent forested perimeter (PFP), area of emergent vegetation, and connectivity. Percent forested perimeter was calculated to evaluate wetland access to $R$. aurora. Perimeter was estimated using both the geometry calculator and the intersect functions (ESRI 2011). The percentage of forested perimeter was calculated by dividing the length of the wetland edge by the total distance of wetland edge that came into direct contact with the "Forest" category described above. The area of emergent vegetation within the wetland was calculated to evaluate the availability of potential breeding habitat because $R$. aurora oviposits on a vegetation brace (Licht 1971). Google imagery base map (2010) and GIS Editor were used to develop emergent vegetation polygons that included only the area within the wetland that might be used as an oviposition brace. Connectivity was calculated to evaluate the effects of fragmentation on the occurrence and abundance of $R$. aurora within study wetlands using the COHESION metric in FRAGSTATS (v4.0) (McGarigal et al. 2012). COHESION estimates the connectivity of habitat potentially used by $R$. aurora dispersing through the landscape classified in a forest/non-forest binary fashion (Schumaker 1996; see Supplementary file FRAGSTATS_COHESION information).

\section{Amphibian presence and abundance}

Rana aurora occurrence and abundance were estimated from visual encounter surveys of egg masses (Heyer et 


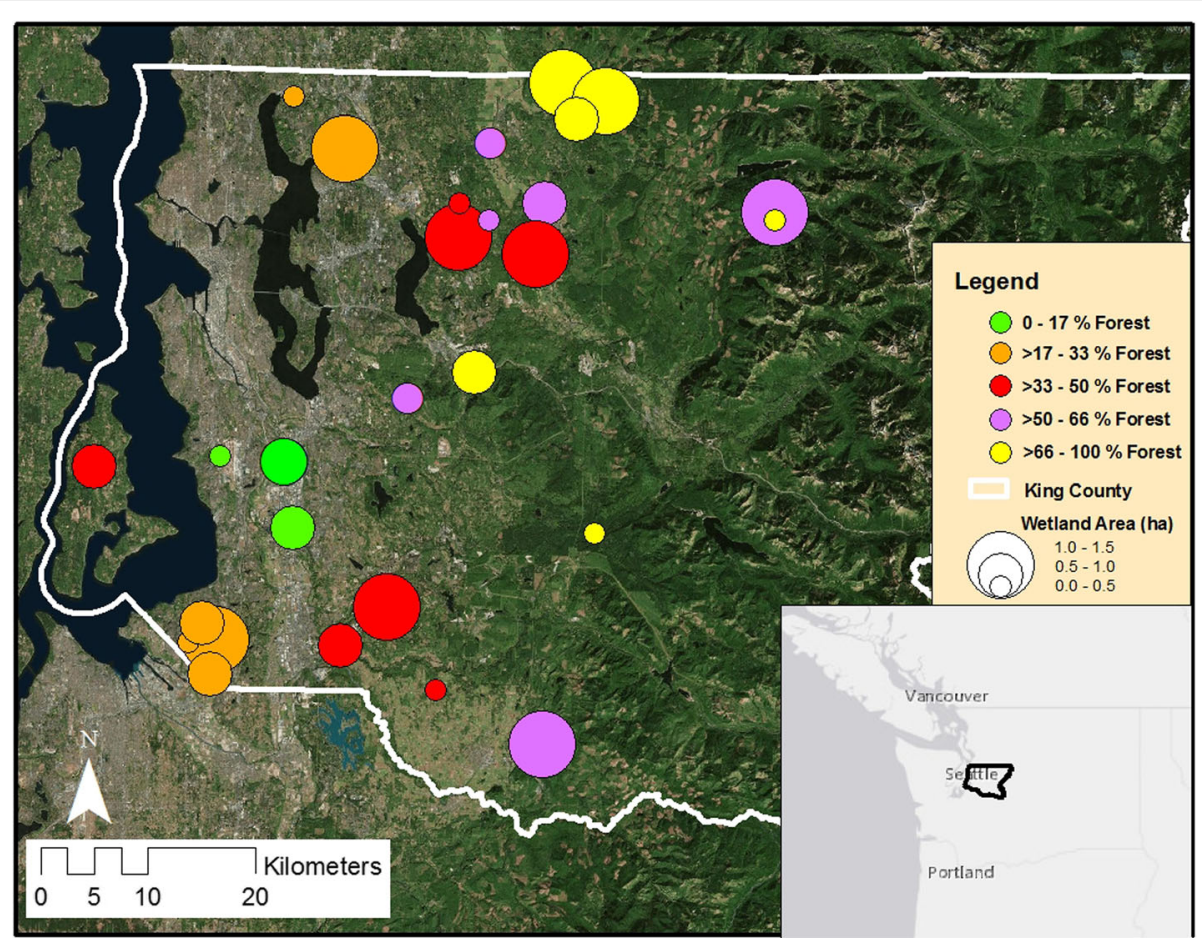

Fig. 1 Study wetlands in King County, Washington State, USA

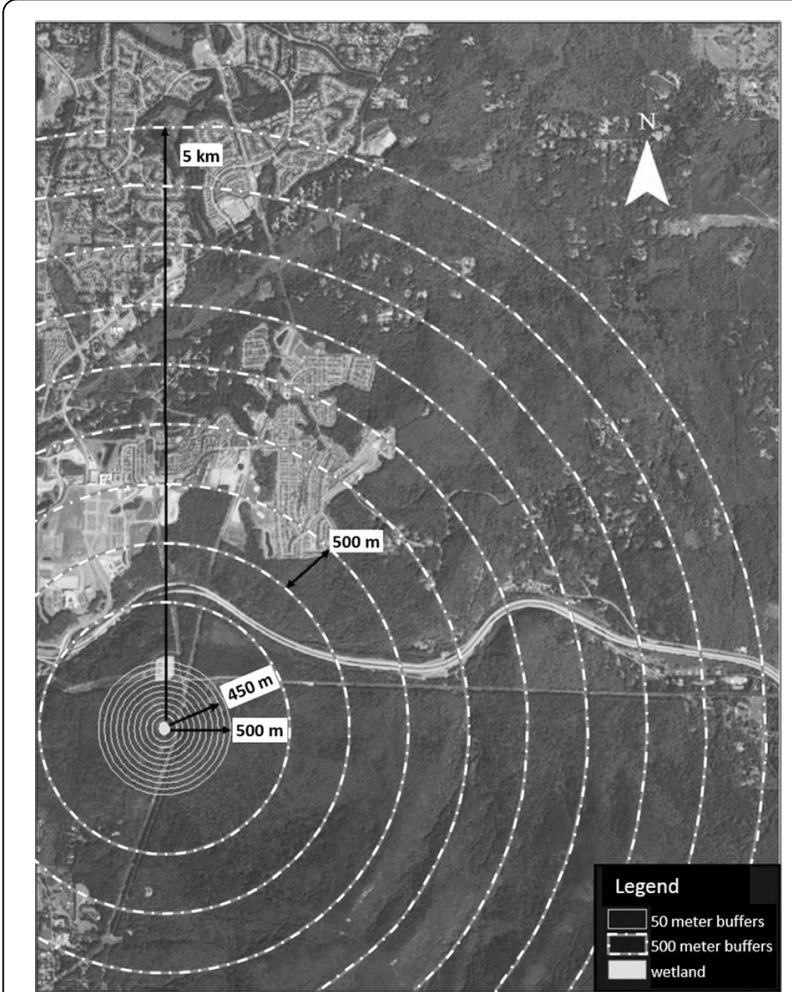

Fig. 2 Example cumulative concentric circles used to identify landscape patterns around the study wetlands. Buffers at 50- and 500-m intervals radiate out from the wetland edge al. 1994) completed between 17 February and 9 May 2012. For $R$. aurora, one egg mass corresponds to one breeding female as multiple clutching is not known and unlikely to occur given oviposition seasonality (see Licht 1969, 1971); hence, egg mass numbers effectively estimate the breeding population size of females and are a good surrogate for breeding population size (e.g., Richter and Azous 2001).

Citizen science volunteers were trained on egg mass identification and survey procedures by the Woodland Park Zoo (Seattle, WA, USA) and by Washington Department of Fish and Wildlife (WDFW) researchers (MPH and CDA). Citizen science volunteers surveyed seven of the wetlands while accompanied by an experienced surveyor. The other 23 wetland surveys utilized the double-observer approach published by Grant et al. (2005) where one experienced observer led the team. Surveys were completed by walking around each wetland to a water depth of $1 \mathrm{~m}$. A flotation device was used to navigate around wetlands where thick woody vegetation and/or deep water impeded effective monitoring from the shore. One site was resurveyed the following year, February and March 2013, due to uncertainty in the quality of the original survey. Given that adult $R$. aurora have an estimated longevity of 10-12 years (Licht 1974), research has shown that the variation in egg mass numbers is typically very low from year to year (Adams 1999; M. Hayes, unpublished data), which supports the 
inclusion of the resurvey data. Additionally, climatic conditions between 2012 and 2013 were very similar and 2013 was not a severe drought year (NOAA 2012 and 2013; NIDIS 2017) —which otherwise might have affected the egg mass production rates of breeding females.

The species identity of each egg mass found was documented. Each wetland was surveyed at least twice to ensure obtaining the maximum estimate of egg mass numbers. If, on the second survey, a wetland still showed signs of recently deposited egg masses (i.e., based on their containing round embryos) adjacent to older egg masses (i.e., containing elongated embryos), the wetland was resurveyed until all egg masses contained elongated embryos that signified the end of ovipositiong. For each wetland, the maximum egg mass count was recorded. Due to evidence that most $R$. aurora breeding females lays eggs within 2 weeks of each other (Licht 1971), the extent of the wetland covered, and the number of surveys conducted, the detection rate was assumed to be $100 \%$. Therefore, if no egg masses were found, occurrence was assumed to be zero.

During egg mass surveys, the presence of aquatic predators including the exotic American bullfrog (Rana (Lithobates) catesbeiana) and fish were recorded.

Two wetlands were excluded from analysis due to the ambiguity in egg mass identification. Both wetlands were from the lowest forest cover category and medium wetland size category.

\section{Data analyses}

Descriptive summaries of the recorded data are presented for the sample of observations investigated in this study. Associations of habitat variables [i.e., percent forest (PCF), connectivity $(\mathrm{CON})$, area of emergent vegetation (EMG), forested perimeter (FRP), wetland area (AREA), bullfrog occurrence (BULL), and fish occurrence (FISH)] and $R$. aurora breeding abundance and occurrence were evaluated using the optimal discriminant analysis (ODA) machinelearning algorithm (Yarnold and Soltysik 1991). The ODA algorithm identifies the threshold value (cutpoint) for an ordered attribute (independent variable)—or the assignment rule for a categorical attribute-that most accurately (optimally) discriminates the different categories (or levels) of the class (dependent) variable for the sample. Identifying the maximum-accuracy (optimal) model involves computing the effect strength for sensitivity (ESS) that is obtained by using every possible cut-point (or assignment rule) to classify sample observations. The ESS is the mean sensitivity obtained by the model across class categories which standardizes, using a $0-100 \%$ scale, where $0 \%$ is the level of accuracy expected by chance and $100 \%$ is the perfect accuracy; negative values indicate lower accuracy than expected by chance. By definition, the optimal model yields the greatest ESS. The following ESS groups are formed based on levels of accuracy: values $<25 \%$ reflect a relatively weak effect; values $<50 \%$ are moderate effects; values $<75 \%$ are relatively strong effects; and values $<90 \%$ are strong effects. Exact statistical significance is computed as a permutation probability, and validity analysis (e.g., single-sample jackknife, called leave-one-out or LOO analysis) is used to assess potential cross-generalizability of the model in correctly classifying new subjects that may differ in their characteristics relative to subjects in the original sample (Yarnold and Soltysik 2005; Yarnold 2017).

Applications involving two or more attributes are analyzed using classification tree analysis (CTA), which constructs optimal models by chaining multiple ODA models together (Yarnold 1996a; Linden and Yarnold 2016). Because of the small sample, in conjunction with the relatively strong effects identified for some attributes (i.e., that produced few misclassifications), CTA models were not possible for the present sample (Yarnold and Soltysik 2016).

A Spearman's rank correlation was used to identify the relationship between percent forest and $R$. aurora breeding abundance within each of the 19 cumulative concentric areas. The non-parametric coefficient was used because abundance data was strongly negatively skewed in a scatterplot matrix of predictor and response variables. To reduce the risk of type I errors where multiple statistical tests were run on different distance ratios measured on the same dataset, the significance limit $(\alpha \leq 0.05)$ was adjusted downwards according to Šidák (1967).

\section{Results}

Rana aurora egg masses were recorded at 21 of the 28 wetlands. Between one and $367 R$. aurora egg masses were recorded at occupied sites (Figs. 3 and 4). Bullfrogs and fish were recorded in nine wetlands, but bullfrogs and fish co-occurred in only three wetlands (Table 1).

\section{Rana aurora occurrence}

Only two variables, connectivity $(\mathrm{CON})$ and percent forest (PCF), of the seven variables examined to predict $R$. aurora occurrence had at least a relatively strong effect using the ODA algorithm; these results were further supported by a LOO analysis (Table 2). The best model for the CON metric, which predicted occurrence at higher values (>96.26), had the stronger effect of the two variables but the PCF metric was only modestly weaker; PCF resulted in the best model when predicted occurrence values were above $28.0 \%$. Training analysis found a third variable, forested perimeter (FRP), with a relatively strong effect, but a LOO analysis did not support this finding $(p>0.05)$. No statistically significant association was found between the occurrence of $R$. aurora and remaining variables examined (all $p>0.05$; Table 2). 


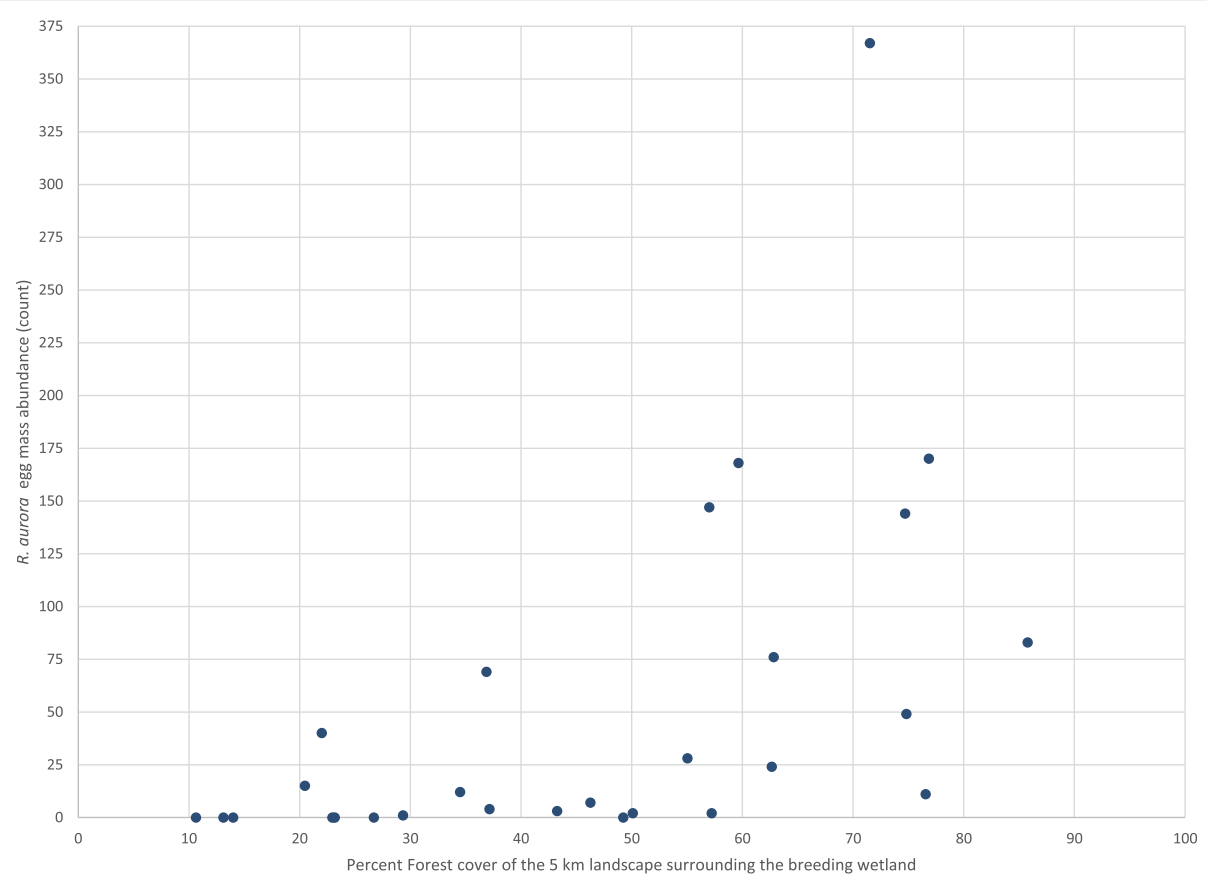

Fig. 3 Relationship of $R$. aurora abundance with percent forest within $5 \mathrm{~km}$ of the wetland edge $(n=28)$

\section{Rana aurora abundance}

Parallel to findings for $R$. aurora occurrence, $\mathrm{CON}$ and PCF yielded best models for $R$. aurora abundance with the strongest levels of accuracy for CON followed by a slightly lower level of accuracy with PCF; these results were supported by LOO analysis (Table 3). Notably, the best CON model predicting $R$. aurora abundance had the same cutpoint, $>96.26$, as the best $\mathrm{CON}$ model for occurrence. Further, the best PCF model for abundance predicted large $R$. aurora populations ( $>69$ egg masses)

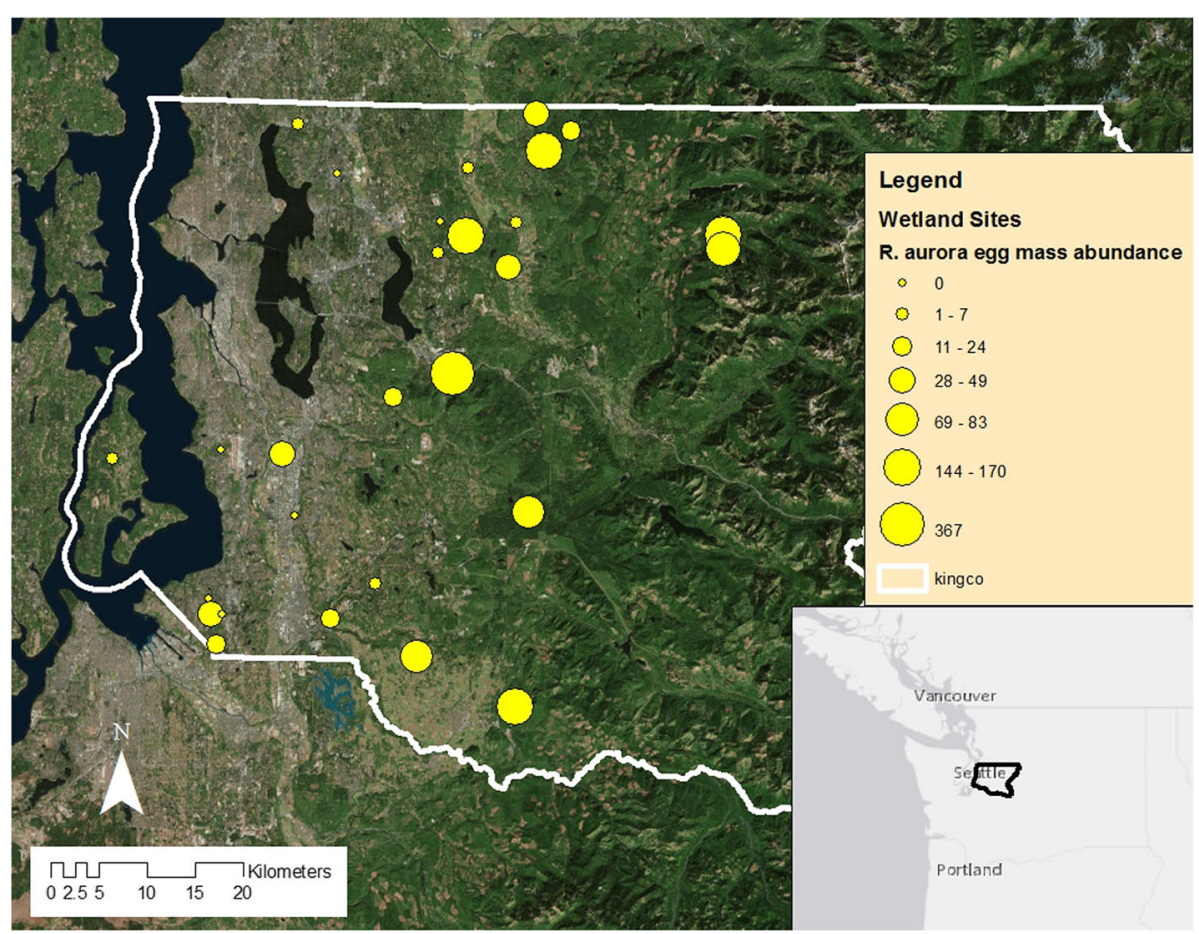

Fig. 4 Study wetland locations with symbol size proportional to the number of egg masses detected at that site 
Table 1 Variables used in $R$. aurora occurrence and abundance models and their descriptive variation

\begin{tabular}{llllllll}
\hline Abbreviation & Description (units) & $\bar{X}$ & $\tilde{X}$ & SD & IQR & CV & Range \\
\hline AREA & Wetland area (ha) & 0.75 & 0.80 & 0.51 & 1.02 & 0.68 & $0.02-1.49$ \\
BULL & Bullfrog presence (bullfrog occupied or not) & 0.32 & 0.00 & 0.48 & 1.00 & 1.48 & $0-1$ \\
CON & Aquatic/terrestrial landscape connectivity & 98.19 & 99.58 & 2.46 & 3.63 & 0.03 & $90.28-99.98$ \\
EMG & Wetland area in emergent vegetation $\left(\mathrm{m}^{2}\right)$ & 2565 & 1464 & 2493 & 3458 & 0.97 & $61-9482$ \\
FISH & Fish presence (fish occupied or not) & 0.32 & 0.00 & 0.48 & 1.00 & 1.48 & $0-1$ \\
FRP & Perimeter of wetland adjacent to forest (\%) & 46.28 & 48.10 & 32.75 & 54.41 & 0.71 & $0-100$ \\
PCF & Percent forest within 5 km of wetland (In[\%]) & 46.23 & 47.76 & 22.33 & 37.81 & 0.48 & $10.64-85.77$ \\
\hline
\end{tabular}

Descriptive variables are the mean $(\bar{X})$, median $(\tilde{X})$, standard deviation $(S D)$, interquartile range (IQR), and coefficient of variation $(C V)$

at forest cover values $>56.0 \%$. However, the strongest effect, based on how it held up in LOO analysis, was for FRP where larger $R$. aurora populations $(>40 \mathrm{egg}$ masses) were found when forest occurred on $>58.6 \%$ of the wetland perimeter. Also, consistent with the findings for $R$. aurora occurrence, no association emerged for abundance (number of egg masses) and wetland area (AREA) or bullfrog occurrence (BULL).

In contrast to the occurrence findings, a moderate strength effect emerged in training and $\mathrm{LOO}$ analysis for fish occurrence (FISH). If fish were present, $R$. aurora populations with at least five egg masses were found. Lastly, although a relatively strong effect was identified for the area of emergent aquatic vegetation (EMG) in training, this effect was not confirmed in LOO analysis (Table 3).

\section{Spatial extent of forest influence on $R$. aurora breeding abundance}

Percent forest (PCF) was positively correlated with $R$. aurora breeding abundance at distances $\geq 200 \mathrm{~m}\left(r_{\mathrm{s}}=0.683\right)$ using the Šidák-corrected rejection criterion $\left(\alpha^{\prime}=0.002\right)$. The strength of the correlation between $R$. aurora breeding abundance initially increased relatively sharply with distance from the breeding site, peaking at a distance of $450 \mathrm{~m}\left(r_{\mathrm{s}}=\right.$
0.778) and thereafter generally declining slightly but remaining high $\left(r_{\mathrm{s}}>0.7\right)$ out to the $5-\mathrm{km}$ distance (Fig. 5).

\section{Discussion/conclusions}

\section{Rana aurora Occurrence and abundance in the terrestrial} habitat

Landscape habitat association research has increasingly identified a positive relationship between forest area and amphibian occurrence (Porej et al. 2004; Cushman 2006). In this study, both $R$. aurora occurrence and breeding abundance had strong to very strong associations with all three forest-linked variables measured around wetlands that $R$. aurora utilized for breeding: the percentage of undeveloped upland forest habitat; the forested perimeter around the wetland; and the connectivity of that forest to the breeding wetland. Response consistency for the forest-linked variables underscores the importance of a forest-related effect for $R$. aurora. Moreover, the fact that all best forest-linked variable models were more robust for breeding abundance than for occurrence suggests that the focus of forest habitat control is linked to $R$. aurora abundance.

Rana aurora has been recaptured in the same season up to $5 \mathrm{~km}$ from their aquatic breeding sites (Hayes et

Table 2 Optimal discriminate analysis models for $R$. aurora occurrence addressing the seven variables examined

\begin{tabular}{|c|c|c|c|c|c|c|c|c|}
\hline \multirow[b]{2}{*}{ Variable } & \multicolumn{5}{|l|}{ Training analysis $^{\mathrm{a}}$} & \multicolumn{3}{|l|}{ LOO analysis $^{b}$} \\
\hline & Model & Number & Accuracy (\%) & $p<$ & ESS & Accuracy (\%) & $p<$ & ESS \\
\hline AREA & - & - & - & 0.9696 & 19.1 & - & - & - \\
\hline BULL & - & - & - & 0.9999 & 4.8 & - & - & - \\
\hline \multirow[t]{2}{*}{ CON } & If $\mathrm{CON} \leq 96.26$ predict no occurrence & 7 & 85.7 & 0.0009 & 81.0 & 71.4 & 0.0039 & 61.9 \\
\hline & If CON > 96.26 predict occurrence & 21 & 95.2 & & & 90.5 & - & - \\
\hline EMG & - & - & - & 0.0921 & 52.4 & - & - & - \\
\hline $\mathrm{FISH}$ & - & - & - & 0.0615 & 42.9 & - & - & - \\
\hline \multirow[t]{2}{*}{ FRP } & If FRP $\leq 50.1 \%$ predict no occurrence & 7 & 100.0 & 0.0238 & 61.9 & - & & \\
\hline & If FRP $>50.1 \%$ predict occurrence & 21 & 61.9 & & & & 0.0604 & 42.9 \\
\hline \multirow[t]{2}{*}{ PCF } & If $\mathrm{PCF} \leq 28.0 \%$ predict no occurrence & 7 & 85.7 & 0.0025 & 76.2 & 71.4 & 0.0095 & 57.1 \\
\hline & If PCF $>28.0 \%$ predict occurrence & 21 & 90.5 & & & 85.7 & & \\
\hline
\end{tabular}

\footnotetext{
${ }^{a}$ Training analysis reveals the maximum-accuracy (optimal) model by using every possible cut-point (or assignment rule) to classify sample observations
} bLeave-one-out or LOO analysis is used to assess potential cross-generalizability of the model. See text for details

Cut points, group sample sizes, and accuracy are shown only for the best models considered significant $(p<0.05)$ 
Table 3 Optimal discriminate analysis models for $R$. aurora breeding abundance addressing the seven variables examined. Presentation is identical to Table 2

\begin{tabular}{|c|c|c|c|c|c|c|c|c|}
\hline \multirow[b]{2}{*}{ Variable } & \multicolumn{5}{|l|}{ Training analysis $^{a}$} & \multicolumn{3}{|l|}{$\underline{\mathrm{LOO} \text { analysis }}{ }^{\mathrm{b}}$} \\
\hline & Model & Number & Accuracy (\%) & $p<$ & ESS & Accuracy $(\%)$ & $p<$ & ESS \\
\hline AREA & - & - & - & 0.1082 & 43.8 & - & - & - \\
\hline BULL & - & - & - & 0.5757 & 20.8 & - & - & - \\
\hline \multirow[t]{2}{*}{ CON } & If $\mathrm{CON} \leq 96.26$ predict $\leq 1$ egg mass & 8 & 87.5 & 0.0001 & 87.5 & 75.0 & 0.0005 & 70.0 \\
\hline & If $\mathrm{CON}>96.26$ predict $>1$ egg mass & 20 & 100.0 & & & 95.0 & & \\
\hline \multirow[t]{2}{*}{ EMG } & If EMG $\leq 2526$ predict $\leq 1$ egg mass & 8 & 100.0 & 0.0448 & 55.0 & - & 0.2184 & 25.0 \\
\hline & If EMG $>2526$ predict $>1$ egg mass & 20 & 55.0 & & & & & \\
\hline \multirow[t]{2}{*}{ FISH } & If $\mathrm{FISH}=0$ predict $\leq 4$ egg masses & 12 & 91.7 & 0.0390 & 41.7 & 91.7 & 0.0241 & 41.7 \\
\hline & If FISH $=1$ predict $>4$ egg masses & 16 & 50.0 & & & 50.0 & & \\
\hline \multirow[t]{2}{*}{ FRP } & If FRP $\leq 58.6 \%$ predict $\leq 40$ egg masses & 19 & 84.2 & 0.0012 & 73.1 & 84.2 & 0.0005 & 73.1 \\
\hline & If FRP $>58.6 \%$ predict $>40$ egg masses & 21 & 88.9 & & & & & \\
\hline \multirow[t]{2}{*}{ PCF } & If $\mathrm{PCF} \leq 56.0 \%$ predict $\leq 69$ egg masses & 21 & 90.00 & 0.0006 & 81.0 & 76.2 & 0.0070 & 61.9 \\
\hline & If PCF $>56.0 \%$ predict $>69$ egg masses & 7 & 100.00 & & & 85.7 & & \\
\hline
\end{tabular}

${ }^{a}$ Training analysis reveals the maximum-accuracy (optimal) model by using every possible cut-point (or assignment rule) to classify sample observations

b Leave-one-out or LOO analysis is used to assess potential cross-generalizability of the model. See text for details

al. 2007). However, little is known about their dispersal patterns. Our spatial analysis revealed that the relationship between $R$. aurora breeding population size and percent forest becomes important at $200 \mathrm{~m}$, peaks at $450 \mathrm{~m}$, but remains high to $5 \mathrm{~km}$ which was the furthest distance examined in this study. Since the correlation between breeding population size and percent forest becomes significant at $200 \mathrm{~m}$, along with the marked increase in the correlation coefficient up to $450 \mathrm{~m}$, this suggests that the forest habitat further from the wetlands maybe more important habitat for $R$. aurora during its migration than the forests bordering the wetlands. During the non-breeding active season, this analysis also supports the importance of forested upland habitat located more than $450 \mathrm{~m}$ from a wetland as food, cover, and migration corridors for $R$. aurora. Telemetry research on the connectivity of the forest patches within $450 \mathrm{~m}$ of wetland margins could help confirm whether the first few hundred meters are mainly used as corridors for $R$. aurora migrating to more distant forest patches. This finding is not unique. Richter and Azous (2001) analyzed the proportion of native amphibian species richness at a wetland and the area of forest land within cumulative concentric circles of 10, 100, 500, and $1000 \mathrm{~m}$ from the wetland edge in King County, Washington State. The relationship was weakest at $10 \mathrm{~m}(R=$ $0.57, P=0.01)$ and strongest at $500 \mathrm{~m}(R=0.66, P=$ 0.004) (Richter and Azous 2001).

Elsewhere, the most parsimonious models for overall salamander diversity and individual models for the

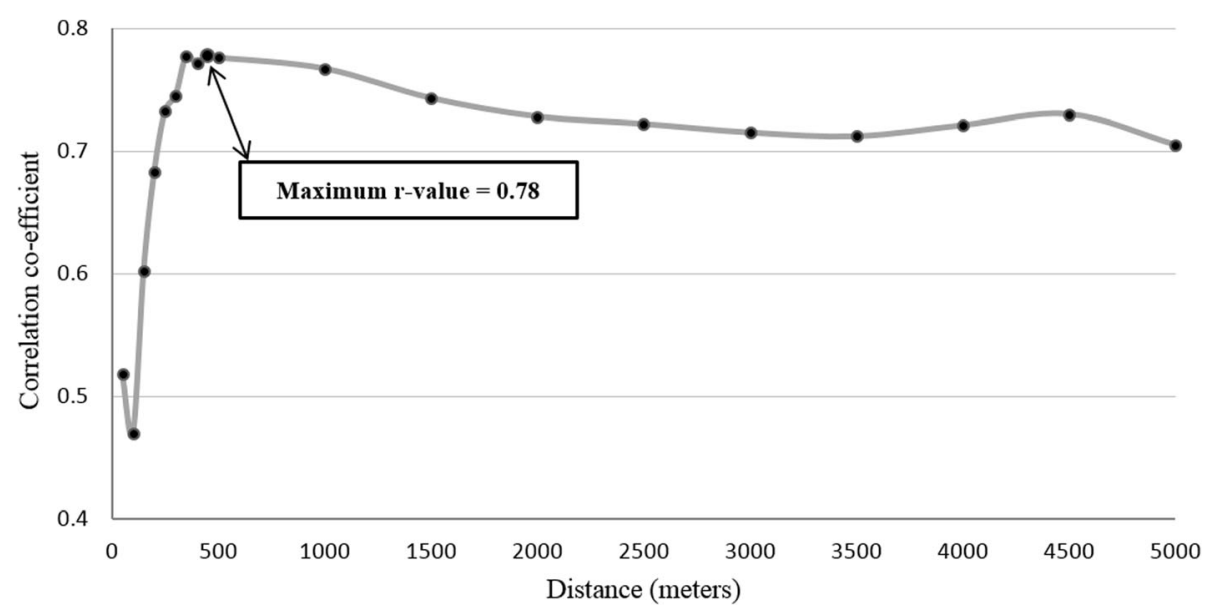

Fig. 5 Relationship between R. aurora abundance and percent forest as a function of distance from wetland 
presence of frogs and salamanders included land-use characteristics found beyond habitat proximate to breeding wetlands (within $200 \mathrm{~m}$ ) (Porej et al. 2004; Semlitsch and Bodie 1998). However, why $R$. aurora travels such long distances is unclear. Habitat further from breeding wetlands may have some positive advantage, either greater food resources or fewer conspecifics to compete with for shelter and food (Haggard 2000). Alternatively, remaining too close to wetlands may pose some disadvantage, such as greater risk of predation (Licht 1974, 1986). Nonetheless, collective study results suggest that persistence of local amphibian populations depend on both wetland-adjacent and more distant upland landscapes. More research on the specific movements and behaviors of local amphibian species could better explain why the relationship of $R$. aurora egg mass counts is more important with forests located at farther distances from the breeding wetland.

A broad consensus exists that broadly dispersing species are adapted to habitat fragmentation (Kareiva and Wennergren 1995) and that such species disperse more easily across unsuitable habitat. However, this study showed connectivity was positively associated with $R$. aurora occurrence and abundance. This suggests it may be necessary to identify alternative causal relationships by which fragmentation exacerbates population declines as a result of habitat loss (Fahrig and Merriam 1985), i.e., adults are unable to utilize non-connected breeding habitat. One way to explore this possibility is to further research the existence of thresholds in forest area and how they may impact $R$. aurora occurrence. If such thresholds exist, identifying them is fundamental to understanding extinction processes and critical to landscape management and conservation design.

This research suggests that a threshold exists between forest cover and $R$. aurora breeding abundance within a range of $5 \mathrm{~km}$ from a wetland (Fig. 4). The cut point for the best ODA model for percent forested habitat identified a threshold at $56.0 \%$ forest cover, i.e., forest covers higher than $56 \%$ resulting in higher $R$. aurora breeding abundance. While this study sample size was too small to claim a definitive threshold, previous research on thresholds of forest fragmentation identified similar thresholds below which the former forest structure and function would no longer be maintained. Franklin and Forman (1987) predicted that major thresholds in fragmentation of the landscape would occur when about $50 \%$ of the forest was converted to non-forest as a result of clear-cutting in the PNW (i.e., amount of edge exceeds interior forest). Vogelmann (1995) reported the greatest increase in forest fragmentation as the landscape cover changed from 100 to $\sim 80 \%$ forest area, with a threshold occurring at $60 \%$. Thresholds of $50-60 \%$ forest cover have also been observed in a few studies on migrating amphibians (Gibbs 1998; Homan et al. 2004). Spotted salamander occurrence at breeding wetlands diminishes at a threshold of $50-60 \%$ forest at both 100 and 1000-m distances (Gibbs 1998; Homan et al. 2004). Lastly, amphibian richness was found to be highest in the Puget Sound basin within wetlands that retain at least $60 \%$ of adjacent area in forestland up to and exceeding $500 \mathrm{~m}$ (Richter and Azous 2001). Critical thresholds are likely to be species-specific, but farmigrating species with a positive association with forest cover and negative association with road density like $R$. aurora are likely to be sensitive biotic indicators to urbanization; urbanization impacts are frequently detected as effects occurring on habitat fragmentation and loss (Pearl et al. 2005).

\section{Rana aurora aquatic habitat relationships}

A commonly preconceived notion of a positive wetland size-amphibian abundance relationship may carry more weight than it should, at least for $R$. aurora. Currently, no research indicates a positive association between $R$. aurora occurrence or abundance with wetland size. Richter and Azous $(1995,2001)$ reported amphibian richness was unrelated to wetland size, whereas Adams (1999) and Pearl et al. (2005) found $R$. aurora abundance and occurrence negatively associated with wetland open water.

This study also found no association between $R$. aurora occurrence or abundance and wetland size for wetlands less than 1.5 ha in size. Lack of association may reflect $R$. aurora's ability to lay multiple egg masses on one oviposition brace (per observation). Other research identifying negative associations with wetland size and $R$. aurora may reflect the secondary effects of exotic predators, i.e., smaller wetlands are less likely to maintain fishes or bullfrogs (Richter and Azous 1995; Adams 1999; Pearl et al. 2005). Additionally, $R$. aurora spend little time seasonally in wetlands, so finding a relationship with wetland size may not be a sensitive variable to measure. Lastly, males do not feed during breeding, so wetland food resources are likely unimportant for them (Licht 1969; Hayes et al. 2008).

If wetland size is less important in $R$. aurora occurrence and abundance, this may provide critical information needed for maintaining this species. Concerns for amphibian species commonly rely more on the status of the breeding wetlands and less on the upland terrestrial habitats (Hayes et al. 2008, Richter and Azous 2001). While wetlands are necessary for $R$. aurora survival, choosing them based on location within the landscape forest matrix may supersede size considerations.

Emergent vegetation was moderately associated with $R$. aurora abundance, but this habitat characteristic did not hold up in LOO. Other studies have shown positive associations with emergent vegetation, but the sample size was too small to explore this relationship in this 
study (Adams 1999; Hazell et al. 2004; Cary 2010). This needs further research at the study sites. Greater area of emergent vegetation may be important for several reasons: $R$. aurora attaching their egg masses to vegetation keep them from floating away or sinking, both of which contribute to mortality (per observation), and vegetation provides larval refuges (Kiesecker et al. 2001).

\section{Aquatic predators and $R$. aurora}

Bullfrog occurrence was unrelated to $R$. aurora occurrence and abundance. This pattern is not particularly surprising since several efforts at addressing $R$. aurora occurrence in the Pacific Northwest have failed to demonstrate a bullfrog effect (Adams 1999, 2000; Curry 2007). Wetlands with fish were expected to show the greatest difference in egg mass abundance because fish effects have been demonstrated on PNW amphibians elsewhere (Adams 1999, 2000; Kiesecker and Blaustein 1998; Monello and Wright 2001). Several factors may contribute to this contradiction that may explain these different results. The two most likely explanations are that in this study fishes were scored collectively (not all fish species are amphibian predators) and neither fish (nor bullfrog) detectability was estimated. Both factors are important limitations for a mobile sometimes cryptic organism.

\section{Habitat protection and land-use planning in urban environments}

Since urbanization can directly eliminate terrestrial habitat, it threatens amphibian persistence and ultimately the ecosystem services they provide. Except for research by Richter and Azous (2001), Pearl et al. (2005), and Ostergaard et al. (2008), studies have not addressed the reliance of PNW lentic-breeding amphibians on terrestrial habitats associated with their aquatic breeding habitat. This study provides the initial context for understanding the nature of the urbanizing threat on $R$. aurora, a species that makes long seasonal movements into forested terrestrial habitats. Importantly, the pivotal findings of this study are that the forested terrestrial habitat and its connectedness to the aquatic habitat, rather than aspects of the aquatic habitat per se, seem to be a fundamental determinant of $R$. aurora's occurrence and abundance. These findings are consistent with what is currently known of $R$. aurora life history, where adults typically spend 8-10 months annually in forested terrestrial habitat and males may not feed at aquatic breeding sites (Hayes et al. 2008). These findings provide a clear rationale for managing wetland resources in concert with available juxtaposed forested uplands to maintain $R$. aurora and potentially other lentic-breeding amphibians on the landscape.

Most conservation policies concerning lentic-breeding amphibians, including those in King County, WA, are focused on wetland protection through fixed-width buffers (Hayes et al. 2008, Richter et al. 2008). These are typically determined based on wetland size, type, function, and surrounding vegetation types (Hayes et al. 2008, Richter and Azous 2001). These policies undervalue the condition of adjacent terrestrial habitat types for amphibians or other wildlife. Regulatory wetland buffers in Washington ranged from 15.2 to $91.4 \mathrm{~m}$ in width (McMillan 1998), but such buffers are much smaller than the $200 \mathrm{~m}$ to $5+\mathrm{km}$ distance that $R$. aurora may need to migrate in order to access its necessary resources. Despite the fact that King County's regulations are acknowledged to be effective within $R$. aurora habitat range, they are still unlikely to maintain landscape-level connectivity needed by $R$. aurora in the face of rapid population growth (Hayes et al. 2008, Richter et al. 2008). Therefore, if the goal is to avoid extirpation of $R$. aurora populations in urbanizing areas of the PNW, jurisdictions should consider protecting sufficiently large-scale terrestrial and breeding habitat connectivity that can facilitate inter-population dispersal and migration across broader landscapes (Semlitsch and Bodie 1998, Hayes et al. 2008).

This study identified multiple aquatic and terrestrial variables that are essential features required by $R$. aurora. This suggests that conservation plans for amphibians should perceive wetlands and the surrounding terrestrial habitat as one ecological unit that needs to be replicated to form a network across a landscape. Such an approach requires the land's governing bodies to plan early in the urbanization process. The feasibility of retaining the minimum amount of terrestrial habitat needed by $R$. aurora is challenging since decisions are made on a managed parcel-by-parcel basis in an urbanizing landscape (Baldwin et al. 2006). For example, the current King County buffer system may limit $R$. aurora from accessing breeding wetlands and other water and upland terrestrial resources beyond those buffers.

Rana aurora makes long annual migrations to and from breeding sites. With extensive travel distances, $R$. aurora is more likely to come into contact with unsuitable habitat and therefore increase the likelihood of their mortality. To control the expansion of unfavorable habitat for $R$. aurora, mapping should integrate the effects of the local landscape on the dispersal and occurrence of $R$. aurora. Also, friction and cost-distance mapping could help conservation planning by identifying a connected network of functioning and accessible aquatic and upland habitats throughout the landscape before development projects are started. As Beninde et al. (2015) emphasized, biodiversity in cities requires space, and $R$. aurora is a prime example of a species with extensive space requirements. A network approach could help conservation strategies move away from the fixed width buffer model, which results in a more fragmented landscape, and toward a landscape with contiguous forests and wetlands that could benefit multiple migratory species (Baldwin et al. 2006). This 
would allow a jurisdiction to set aside land and make efforts to purchase development rights or use other methods to preserve upland habitats at high enough percentages and distances from the breeding ponds to support $R$. aurora. Such an approach is greatly preferable to restoration efforts that favor exclusively large steepsided and deep wetlands, which lack large emergent vegetation zones, and are placed in areas of high development with high road densities, or areas with permanent hydroperiods that support fish and bullfrog predators. These projects are a more costly, not typically ecologically successful, and commonly call for wetland relocation resulting in the extirpation of local populations.

This study suggests that the area of undeveloped terrestrial habitat juxtaposed with breeding ponds may represent a fundamental control on amphibian population size for some species. The patterns observed for $R$. aurora support the need for more research on how to manage across varied forested PNW landscapes. This research also suggests that urban development policies should begin to consider and plan for maintaining high-quality habitat on the landscape scale. Importantly, this study reinforces the idea that landscape issues such as habitat complementation deserve exploration among other lentic-breeding amphibians that seasonally require both aquatic and terrestrial habitats.

\section{Abbreviations \\ AREA: Wetland area; BULL: Bullfrog occurrence; CON: Connectivity as reported by COHESION in FRAGSTATS v4.0; CTA: Classification tree analysis; EMG: Area of emergent vegetation; ESS: Effect strength for sensitivity; FISH: Fish occurrence; FRP: Forested perimeter; GIS: Geographic information systems; GPS: Global positioning system; LOO: Leave-one-out analysis; ODA: Optimal discriminant analysis; PCF: Percent forest; PNW: Pacific Northwest of the United States; R. aurora: Rana aurora, northern red-legged frog; WDFW: Washington Department of Fish and Wildlife}

\section{Acknowledgements \\ We thank G. Brendon, T. Wilson, L. Dalton, C. Brewer, N. Saetern, H. Litzenberger, Y. Li, R. Turner, A. Beaty, N. Johnson, Y. Huang, M. Shelton, L. Hannon, and A. Yahnke for the help with the fieldwork; S. Gmur for the GIS support; and L. Conquest for the statistical support. The conducted fieldwork was under a programmatic permit that covers Washington Department of Fish and Wildlife employees and their partners in the course of their work; this permit requires following the American Society of Ichthyologists and Herpetologists guidelines for the use of live amphibians and reptiles in field and laboratory research. Thank you to J. Mears, K. Remine, and the Woodland Park Zoo's Amphibian Monitoring Program for providing data collected by the citizen volunteers at our research sites.}

\section{Funding}

There was no funding awarded for this research.

\section{Availability of data and materials}

The dataset supporting the conclusions of this article is included within the article.

\section{Authors' contributions}

LG designed the study; collected, analyzed, and interpreted the data; and wrote and revised the manuscript. MH generated the idea, designed the study, interpreted the data, and wrote and revised the manuscript. KV designed the study, interpreted the data, and revised the manuscript. PY analyzed and interpreted the data. All authors participated in its design and coordination and helped to draft the manuscript. All authors read and approved the final manuscript.

Ethics approval and consent to participate

Not applicable

\section{Consent for publication}

Not applicable

\section{Competing interests}

The authors declare that they have no competing interests.

\section{Publisher's Note}

Springer Nature remains neutral with regard to jurisdictional claims in published maps and institutional affiliations.

\section{Author details}

${ }^{1}$ College of Forestry, Oregon State University, 996 Jefferson St, Eugene, OR 97402, USA. ${ }^{2}$ Science Division, Habitat Program, Washington Department of Fish and Wildlife (WDFW), 600 Capitol Way North, Olympia, WA 98501-1091, USA. ${ }^{3}$ School of Environmental and Forest Sciences (SEFS), University of Washington, Box 352100, Seattle, WA 98195-2100, USA. ${ }^{4}$ Optimal Data Analysis, LLC, 6348 N. Milwaukee Ave., \#163, Chicago, IL 60646, USA. ${ }^{5} 11040$ 104th Ave NE, Kirkland, WA 98033-4423, USA. ${ }^{6}$ District 12, King County, Washington Department of Fish and Wildlife (WDFW), Region 4, 16018 Mill Creek Blvd, Mill Creek, WA 98012, USA. ${ }^{7}$ King County Department of Natural Resources and Parks (DNRP), Water and Land Resources Division (WLRD), King Street Center, 201 S Jackson St. Suite 600, Seattle, WA 98104, USA.

Received: 20 June 2017 Accepted: 27 November 2017

Published online: 18 December 2017

\section{References}

Adams MJ (1999) Correlated factors in amphibian decline: exotic species and habitat change in western Washington. J Wild life Manage 63(4):1162-1171

Adams MJ (2000) Pond permanence and the effects of exotic vertebrates on anurans. Ecol Appl 10(2):559-568

Baldwin RF, Calhoun AJK, DeMaynadier PG (2006) Conservation planning for amphibian species with complex habitat requirements: a case study using movements and habitat election of the wood frog Rana sylvatica. J Herpetol 40(4):442-453

Beninde J, Veith M, Hochkirch A (2015) Biodiversity in cities needs space: a metaanalysis of factors determining intra-urban biodiversity variation. Ecol Lett. https://doi.org/10.1111/ele.12427

Butler BJ, Swenson JJ, Alig RJ (2004) Forest fragmentation in the Pacific Northwest: quantification and correlations. Forest Ecol and Manag 189(1):363-373

Cary JA (2010) Determining habitat characteristics that predict oviposition site selection for pond breeding northern red-legged frogs (Rana aurora) in Humboldt County, California. Master's Thesis. Humboldt State University

Cole EC, McComb WC, Newton M, Chambers CL, Leeming JP (1997) Response of amphibians to clearcutting, burning, and glyphosate application in the Oregon coast range. J Wildlife Manage 61(3):656-664

Curry TR (2007) Amphibian distribution and reproductive success in hydrologically managed wetlands and municipal stormponds. Master's Thesis, Portland State University

Cushman SA (2006) Effects of habitat loss and fragmentation on amphibians: a review and prospectus. Biol Conserv 128(2):231-240

Department of Commerce (DOC), National Ocean Service (NOS), Coastal Services Center (CSC) (2008) WA_2006.img. Dec. 22, 2008 edn. NOAA's Ocean Service, Coastal Services Center (CSC)

Dodd CK Jr, Smith LL (2003) Habitat destruction and alteration: historical trends and future prospects for amphibians. In: Semlitsch RD (ed) Amphibian Conservation. Smithsonian Institution, Washington, DC, pp 94-112

Dvornich KM, McAllister KR, Aubry KB (1997) Volume 2-amphibians and reptiles of Washington State: location data and predicted distributions. In: Cassidy KM, Grue CE, Smith MR, Dvornich KM (eds) Washington State Gap Analysis-final report. Washington Cooperative Fish and Wildlife Research Unit, University of Washington, Seattle, pp 1-146

ESRI (2011) ArcGIS Desktop: Release 10. Environmental Systems Research Institute, Redlands 
Fahrig L, Merriam G (1985) Habitat patch connectivity and population survival. Ecology 66(6):1762-1768

Franklin JE, Forman RTT (1987) Creating landscape patterns by forest cutting: ecological consequences and principles. Landscape Ecol 1(1):5-18

Franklin JF, Dyrness CT (1973) Natural vegetation of Oregon and Washington. USDA Forest Service General Technical Report, Pacific Northwest Forest and Range Experiment Station, PNW-8

Gibbs J (1998) Distribution of woodland amphibians along a forest fragmentation gradient. Landscape Ecol 13(4):263-268

Gibbs JP (2000) Wetland loss and biodiversity conservation. Conserv Biol 14(1):314-317

Google imagery base map (2010) ESRl, DigitalGlobe, GeoEye, Earthstar Geographics, CNES/Airbus DS, USDA, USGS, AeroGRID, IGN, and the GIS User Community.

Grant EHC, Jung RE, Nichols JD, Hines JE (2005) Double-observer approach to estimating egg mass abundance of pool-breeding amphibians. Wetl Ecol Manag 13(3):305-320

Haggard JAG (2000) A radio telemetric study of the movement patterns of adult. Master's Thesis, Humboldt State University

Hayes MP, Pearl CA, Rombough CJ (2001) Rana aurora aurora (northern redlegged frog). Mov. Herpetol Rev 32(1):35-36

Hayes MP, Quinn T, Richter KO, Schuett-Hames J, Serra Shean J (2008) Maintaining lentic-breeding amphibians in urbanizing landscapes: the case study of the northern red-legged frog (Rana aurora). In: Mitchell JC, Jung RE, Bartholomew B (eds). Urban Herpetology. Society for the Study of Amphibians and Reptiles, Herpetological Conservation 3, Salt Lake City, pp 445-461

Hayes MP, Rombough CJ, Hayes CB (2007) Rana aurora (northern red-legged frog). Mov. Herpetol Rev 38(2):192-193

Hazell D, Hero J-M, Lindenmayer D, Cunningham R (2004) A comparison of constructed and natural habitat for frog conservation in an Australian agricultural landscape. Biol Conserv 119(1):61-71

Heyer WR, Donnelly MA, McDiarmid RW, Hayek L-AC, Foster MS (1994) Measuring and monitoring biological diversity: standard methods for amphibians. Smithsonian Institution, Washington, DC

Homan RN, Windmiller BS, Reed JM (2004) Critical thresholds associated with habitat loss for two vernal pool-breeding amphibians. Ecol Appl 14(5):1547-1553

Kareiva P, Wennergren U (1995) Connecting landscape patterns to ecosystem and population processes. Nature 373(6512):299-302

Kiesecker JM, Blaustein AR (1998) Effects of introduced bullfrogs and smallmouth bass on microhabitat use, growth, and survival of native red-legged frogs (Rana aurora). Conserv Biol 12(4):776-787

Kiesecker JM, Blaustein AR, Miller CL (2001) Potential mechanisms underlying the displacement of native red-legged frogs by introduced bullfrogs. Ecology 82(7):1964-1970

King County (2010) Wetlands defined from Critical Area Ordinance surveys in King County. King County, Washington

Knutson MG, Sauer JR, Olsen DA, Mossman MJ, Hemesath LM, Lannoo MJ (1999) Effects of landscape composition and wetland fragmentation on frog and toad abundance and species richness in lowa and Wisconsin, USA. Conserv Biol 13(6):1437-1446

Laan R, Verboom B (1990) Effects of pool size and isolation on amphibian communities. Biol Conserv 54(3):251-262

Lehtinen RM, Galatowitsch SM, Tester JR (1999) Consequences of habitat loss and fragmentation for wetland amphibian assemblages. Wetlands 19(1):1-12

Licht LE (1969) Comparative breeding behavior of red-legged frog (Rana aurora aurora) and western spotted frog (Rana pretiosa pretiosa) in southwestern British Columbia. Can J Zool 47(6):1287-1299

Licht LE (1971) Breeding habits and embryonic thermal requirements of the frogs, Rana aurora aurora and Rana pretiosa pretiosa, in the Pacific Northwest. Ecology 52(1):116-124

Licht LE (1974) Survival of embryos, tadpoles, and adults of the frogs Rana aurora aurora and Rana pretiosa pretiosa sympatric in southwestern British Columbia. Can J Zool 52(5):613-627

Licht LE (1986) Food and feeding-behavior of sympatric red-legged frogs, Rana-aurora, and spotted frogs, Rana-pretiosa, in southwestern BritishColumbia. Can Field Nat 100(1):22-31

Linden A, Yarnold PR (2016) Using data mining techniques to characterize participation in observational studies. J Eval Clin Pract 22(6):839-847

Luck GW (2007) A review of the relationships between human population density and biodiversity. Biol Rev 82:607-645
Martin KJ, McComb BC (2003) Amphibian habitat associations at patch and landscape scales in the central Oregon Coast Range. J Wildlife Manage 67(4):672-683

McGarigal K, Cushman S, Ene E (2012) FRAGSTATS v4: spatial pattern analysis program for categorical and continuous maps. Computer software program produced by the authors at the University of Massachusetts, Amherst. Available at the following web site: http://www. umass.edu/landeco/ research/fragstats/fragstats.html

McKee JK, Sciulli PW, Fooce CD, Waite TA (2004) Forecasting global biodiversity threats associated with human population growth. Biol Conserv 115(1):161-164

McKinney ML (2002) Urbanization, biodiversity and conservation. Bioscience 52(10):883-890

McMillan A (1998) How ecology regulates wetlands: an introduction to regulatory authority, wetland definitions and delineation, wetland characterization and function assessment, wetland mitigation, buffers, and more. Washington State Department of Ecology, Olympia

Monello RJ, Wright RG (2001) Predation by goldfish (Carassius auratus) on eggs and larvae of the eastern long-toed salamander (Ambystoma macrodactylum columbianum). J Herpetol 35(2):350-353

National Integrated Drought Information System (NIDIS) (2017) US dought monitor-Washington. Available at the following website: https://www. drought.gov/drought/states/washington

National Oceanic and Atmospheric Administration (NOAA) (2012 and 2013) Station data inventory, access \& history. Seattle Tacoma International Airport, WA. Available at the following website: https://www.ncdc.noaa.gov/cdoweb/datasets/GHCND/stations/GHCND:USW00024233/detail

Nussbaum RA, Brodie ED Jr, Storm RM (1983) Amphibians and reptiles of the Pacific Northwest. University Press of Idaho, Moscow

Ostergaard EC, Richter KO, West SD (2008) Amphibian use of stormwater ponds in the Puget Lowlands of Washington, USA. In: Mitchell JC, Jung RE, Bartholomew B (eds) Urban Herpetology. Society for the Study of Amphibians and Reptiles, Herpetological Conservation 3, Salt Lake City, pp 259-270

Pearl CA, Adams MJ, Leuthold N, Bury RB (2005) Amphibian occurrence and aquatic invaders in a changing landscape: Implications for wetland mitigation in the Willamette Valley, Oregon, USA. Wetlands 25(1):76-88

Pearl CA, Hayes MP, Haycock R, Engler JD, Bowerman J (2005) Observations of interspecific amplexus between western North American ranid frogs and the introduced American bullfrog (Rana catesbeiana) and an hypothesis concerning breeding interference. Am Midl Nat 154(1):126-134

Pivo G (1996) Toward sustainable urbanization in Mainstreet Cascadia. Cities 13(5):339-354

Pope SE, Fahrig L, Merriam HG (2000) Landscape complementation and metapopulation effects on Leopard frog populations. Ecology 81(9):2498-2508

Porej DP, Micacchion M, Hetherington TE (2004) Core terrestrial habitat for conservation of local populations of salamanders and wood frogs in agricultural landscapes. Biol Conserv 120(3):399-409

Richter KO, Azous AL (1995) Amphibian occurrence and wetland characteristics in the Puget-Sound basin. Wetlands 15(3):305-312

Richter KO, Azous AL (2001) Amphibian distribution, abundance, and habitat use. In: Wetlands and urbanization: implications for the future. Lewis Publishers, Boca Raton, pp 143-165

Richter KO, Kerr D, Blessing B (2008) Buffer-only wetland protection: implications for pond-breeding amphibians. In: Mitchell JC, Jung RE, Bartholomew B. Urban Herpetology. Society for the Study of Amphibians and Reptiles, Herpetological Conservation 3. Salt Lake City, pp 489-504

Scheffers BR, Paszkowski CA (2012) The effects of urbanization on North American amphibian species: Identifying new directions for urban conservation. Urban Ecosystems 15(1):133-147

Schumaker NH, (1996) Using Landscape Indices to Predict Habitat Connectivity, Ecology 77(4):1210-1225

Semlitsch RD (2000) Principles for management of aquatic-breeding amphibians. J Wildlife Manage 64(3):615-631

Semlitsch RD, Bodie JR (1998) Are small, isolated wetlands expendable? Conserv Biol 12(5):1129-1133

Semlitsch RD, Bodie JR (2003) Biological criteria for buffer zones around wetlands and riparian habitats for amphibians and reptiles. Conserv Biol 17(5):1219-1228

Šidák ZK (1967) Rectangular confidence regions for the means of multivariate normal distributions. J Am Stat Assoc 62(318):626-633

Trombulak SC, Frissell CA (2000) Review of the ecological effects of roads on terrestrial and aquatic communities. Conserv Biol 14(1):18-30 
US Census Bureau (2015) State \& county quick facts. Washington: King County. https://www.census.gov/quickfacts/fact/table/kingcountywashington,WA PST045216

Vogelmann JE (1995) Assessment of forest fragmentation in southern NewEngland using remote-sensing and geographic information-systems technology. Conserv Biol 9(2):439-449

White D, Minotti PG, Barczak MJ, Sifneos JC, Freemark KE, Santelmann MV, Steinitz CF, Kiester AR, Preston EM (1997) Assessing risks to biodiversity from future landscape change. Conserv Biol 11(2):349-360

WOFM [Washington Office of Financial Management] (2012) Washington State County Population Projects for growth management. Office of Financial Management, Olympia

Yarnold PR (1996) Discriminating geriatric and non-geriatric patients using functional status information: an example of classification tree analysis via UniODA. Educ Psychol Meas 56(4):656-667

Yarnold PR (2017) What is optimal data analysis? Optimal Data Analysis 6:26-42 Yarnold PR, Soltysik RC (1991) Theoretical distributions of optima for univariate discrimination of random data. Dec Sci 22(4):739-752

Yarnold PR, Soltysik RC (2005) Optimal data analysis. A guidebook with software for Windows. American Psychological Association, Washington, D.C

Yarnold PR, Soltysik RC (2016) Maximizing predictive accuracy. Optimal data analysis, Chicago. https://doi.org/10.13140/RG.2.1.1368.3286

\section{Submit your manuscript to a SpringerOpen ${ }^{\circ}$ journal and benefit from:}

- Convenient online submission

- Rigorous peer review

- Open access: articles freely available online

- High visibility within the field

- Retaining the copyright to your article

Submit your next manuscript at $\gg$ springeropen.com 